\title{
Experimental Analysis of Indentation Morphologies After Spherical Indentation
}

\author{
Giuseppe Pintaude*, Alessandro Roberto Hoechele
}

\author{
Academic Department of Mechanics - DAMEC, Federal University of Technology Paraná - UTFPR, \\ Av. Sete de Setembro, 3165, CEP 80230-901, Curitiba, PR, Brazil
}

Received: June 6, 2012; Revised: August 26, 2013

\begin{abstract}
Indentation morphologies depend on the mechanical properties of materials, especially the strainhardening exponent and yield strength-to-elastic modulus ratio. Hernot et al. ${ }^{1}$ described a model that can be used to obtain the indentation morphology index from properties determined in tensile tests. The model is used here with two aluminum alloys and 1020 steel tested under spherical indentation with different loads and ball diameters. There was good agreement between the values predicted by the model and the experimental findings for all the materials tested except partially recovered AA1350 aluminum alloy (H24 condition). This exception is discussed and a possible explanation for it is sought in other experimental deviations and in microstructural inhomogeneities.
\end{abstract}

Keywords: hardness, aluminum alloy, indentation, mechanical properties

\section{Introduction}

Indentation morphologies (pile-up/sink-in) depend on the mechanical properties of materials, especially the strain-hardening exponent $(n)$ and yield strength-to-elastic modulus ratio $(Y / E)$. Pile-up and sink-in can hamper measurement of material properties ${ }^{2}$ and are considered to be the main problem associated with some methodologies for determining the elastic modulus using instrumented indentation testing. For example, Franco et al. ${ }^{3}$ confirmed this effect for a broad range of materials and found that those materials that exhibited pile-up produced different elastic modulus values in instrumentation indentation tests and tensile tests. Other methodologies, known as reverse analysis, have been proposed to overcome the pile-up effect ${ }^{4,5}$. One of these was tested and performed well when used with polymers ${ }^{6}$.

After exhaustive use over many years of the results reported by Norbury and Samuel ${ }^{8}$, new experimental results relating strain-hardening exponent and indentation morphologies in spherical indentation were published ${ }^{7}$.

Pintaude et al. ${ }^{7}$ observed that the behavior of two metals (316 L stainless steel and AA1350-H24 aluminum alloy) in deep spherical indentation tests was not described by any model ${ }^{9-12}$ and discussed this finding in the light of the metallurgical properties of these materials.

In this context, this manuscript aims to compare the indentation morphologies for different metals calculated using models described by Hernot et al. ${ }^{1}$ and Cheng and Cheng ${ }^{13}$ and to show how they explain the findings in the study by Pintaude et al. ${ }^{7}$. Both models are based on numerical simulations. In the case of the paper by Hernot et al. ${ }^{1}$, a series of equations were derived, as the amount of pile-up or sink-in depends on the ratio of the maximum indentation depth to ball radius $(h / R)$ and on the mechanical properties ( $n$ and $Y / E$ ) extracted from tensile

*e-mail: giuseppepintaude@gmail.com tests. Cheng and Cheng ${ }^{13}$ make use of dimensional analysis in addition to numerical simulation to obtain the indentation morphology index and present the results graphically for each value of strain-hardening exponent.

\section{Experimental}

Two aluminum alloys and 1020 steel were tested in spherical indentation tests using different ball diameters and loads. For practical reasons, the ratio of the indentation diameter $(d)$ to ball diameter $(D)$ should be kept in the range 0.24 to 0.6 in this type of test ${ }^{14}$. Accordingly, only those combinations of load and ball diameter shown in Table 1 were used, resulting in the following values for load $(L)$ /square of ball diameter $\left(D^{2}\right): 49.05 \mathrm{~N} / \mathrm{mm}^{2}$ for AA1350 aluminum alloy; $98.1 \mathrm{~N} / \mathrm{mm}^{2}$ for $6063-\mathrm{T} 5$; and $294.3 \mathrm{~N} / \mathrm{mm}^{2}$ for 1020 steel. For each condition, a minimum of 45 indentations were performed.

AA1350 alloy (0.145 wt. \% Fe - 0.007 wt. \% Si) was heat treated to produce different levels of hardening: H18 (work-hardened), H24 (partially recovered) and O condition (totally recovered). A wide range of treatments were carried out to identify cycles that would provide different hardness values for the AA1350 alloy. Based on these treatments, the $\mathrm{H} 24$ condition was achieved after 6 hours at $330{ }^{\circ} \mathrm{C}$, and for the $\mathrm{O}$ condition an isothermal temperature of $400{ }^{\circ} \mathrm{C}$ was applied for 6 hours. A summary of the heat treatments can be seen in Table 2 . A detailed study ${ }^{15}$ tested a roughly similar aluminum alloy (0.81 wt. \% Fe - 0.65 wt. \% Si) under different true strains ( 0.2 to 3.7 ) and for all cases, including an as-cast condition, $400{ }^{\circ} \mathrm{C}$ was always sufficient to ensure fully recrystallized grains.

For the indentation experiments, the specimens were machined and the surfaces prepared to a finish equivalent to a sanding performed with 1200 grit to ensure they were flat and to avoid scratches or grooves. After indentation, the 
residual profiles were determined using a $2 \mathrm{D}$ profilometer with the specimens fastened by a device (details elsewhere ${ }^{7}$ ) to prevent them moving while measurements were being taken. We use the following equation and symbols to describe the amount of pile-up or sink-in:

$h_{C}=i m i . h$

where

imi is the indentation morphology index,

$h_{C}$ is the contact depth $(=s+h$, where $s$ is the pile-up depth), and

$h$ is the indentation depth at maximum load.

Values of imi higher than 1 indicate that pile-up has occurred, while values less than 1 correspond to sink-in. Figure 1 shows the parameters described in Equation 1 and a cross section of an indentation profile.

All the materials were also submitted to tensile tests in an MTS810 tester with a $10 \mathrm{kN}$ load cell. The strain rate used was $0.083 \mathrm{~mm} / \mathrm{s}$ and the strain-hardening exponent was obtained following the procedures described in ASTM E646-07 ${ }^{[16]}$.

A minimum of three samples were tested for each type of material. The results are shown in Table 3.

The materials tested have strain-hardening exponents of less than 0.4 , a necessary condition for the model proposed by Hernot et al. ${ }^{1}$. The following equations described by Hernot et al. ${ }^{1}$ were therefore used with the mechanical properties obtained in tensile tests:

$i m i=M^{2 / N}\left(2 \frac{h}{R}\right)^{(2-N) / N}$

where

$R$ is the ball radius, and $M$ and $N$ are defined as

$M=\frac{(1.45+28.55 n+1745 Y / E)(1-0.5 n+20 Y / E)}{(1+21.4 n+1020 Y / E)(1+0.4 n+60 Y / E)}$

$N=\frac{(1.9+12.5 n+570 Y / E)(1+0.1 n)}{(1+6.8 n+340 Y / E)}$

Table 1. Load $(L)$ and ball diameter $(D)$ combinations used in the spherical indentation tests.

\begin{tabular}{cc}
\hline Ball diameter, $\mathbf{~ m m}$ & Load, $\mathbf{N}$ \\
\hline 2.5 & $306.56,613.125$ or 1834.5 \\
3.175 (only for AA1350) & 494.42 \\
5 & $1226.25,2452.5$ or 7357.5 \\
10 (not used for AA1350) & 9810 or 29430 \\
\hline
\end{tabular}

\section{Results and Discussion}

Figure 2 shows the experimental values of imi versus the values calculated using the model described by Hernot et al. ${ }^{1}$. An important limitation when using this model is the value of $Y / E$, which should be greater than $1 / 4200$. In the case of AA1350 aluminum alloy, it is worthwhile to note that its $Y / E$ is close to this limit.

The experimental values obtained for 6063-T5 alloy and 1020 steel were predicted reasonably well by the model, as were the results for recovered AA1350 aluminum alloy despite this material's low $Y / E$. Taking a typical value of $i m i$ for AA1350-O (1.0), it is clear from Figure 3 that the results of the numerical simulation described by Cheng and Cheng ${ }^{13}$ do not agree with the experimental values for this case.

Figure 3 shows that a material with $i m i=1.0$ would correspond to an experimental value of $Y / E>0.001$, which does not agree with the values calculated using the theoretical model even if allowance is made for the fact that the strain-hardening exponents used in the experimental approach and the numerical simulation were different $(0.28$ for the experimental approach and 0.3 for the numerical simulation). AA1350-O aluminum alloy

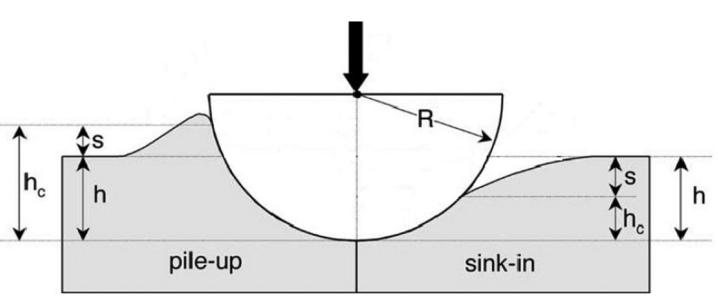

Figure 1. Cross section of an indentation profile showing the ball radius $(\mathrm{R})$, contact depth $(\mathrm{hC})$, pile-up depth (s) and indentation depth at maximum load (h).

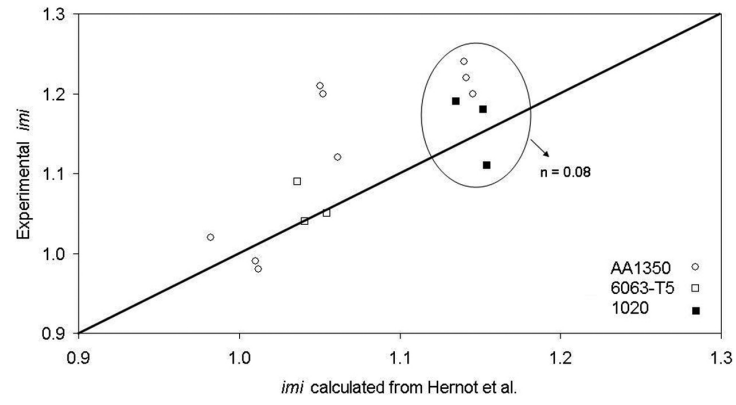

Figure 2. Experimental values of imi from indentation profiles versus values calculated using the model described by Hernot et al. ${ }^{1}$.

Table 2. Heat treatment and Brinell hardness for each type of material and temper (where applicable).

\begin{tabular}{clc}
\hline Material and temper (where applicable) & \multicolumn{1}{c}{ Heat treatment } & Hardness, HB \\
\hline AA1350-H18 & Work hardened (as received) & $36.5 \pm 0.8$ \\
AA1350-H24 & Partially recovered $-330{ }^{\circ} \mathrm{C}$ for $6 \mathrm{~h}$ & $30 \pm 1$ \\
AA1350-O & Totally recovered $-400{ }^{\circ} \mathrm{C}$ for $6 \mathrm{~h}$ & $19 \pm 0.8$ \\
$6063-\mathrm{T} 5$ & Artificially aged (as received) & $82.5 \pm 12.5$ \\
1020 steel & As rolled & $145 \pm 15$ \\
\hline
\end{tabular}


Table 3. Yield strength $(Y)$, elastic modulus $(E)$ and strain-hardening exponent $(n)$ for the different materials.

\begin{tabular}{ccccc}
\hline $\begin{array}{c}\text { Material and temper } \\
\text { (where applicable) }\end{array}$ & $Y, \mathbf{M P a}$ & $E, \mathbf{G P a}$ & $n$ & $Y / E$ \\
\hline AA1350-H18 & $82 \pm 4$ & $57 \pm 3$ & $0.08 \pm 0.01$ & 0.0014 \\
AA1350-H24 & $75 \pm 20$ & $63 \pm 8$ & $0.17 \pm 0.01$ & 0.0118 \\
AA1350-O & $35 \pm 1.5$ & $56 \pm 7$ & $0.28 \pm 0.04$ & 0.0006 \\
6063-T5 & $174 \pm 9$ & $64 \pm 2$ & $0.13 \pm 0.007$ & 0.0027 \\
1020 steel & $437 \pm 44$ & $210 \pm 10$ & $0.08 \pm 0.008$ & 0.0020 \\
\hline
\end{tabular}

imi

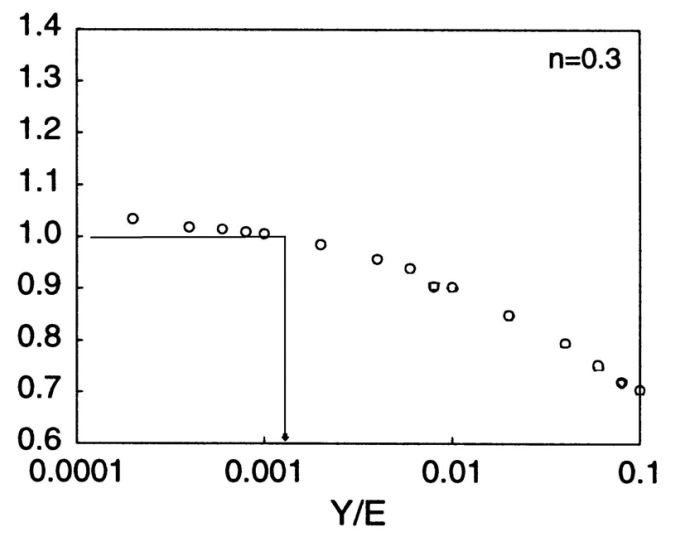

Figure 3. Numerical simulation described by Cheng and Cheng ${ }^{13}$ showing the variation in $i m i$ with $Y / E$ for a material with $n=0.3$. The experimental value of $Y / E$ corresponding to $i m i=1.0$ is marked.

has a $Y / E$ value of 0.0006 , smaller than that indicated in Figure 3. Consequently, the model proposed by Hernot et al. ${ }^{1}$ produced better results for AA1350-O alloy than the numerical simulation described by Cheng and Cheng ${ }^{13}$.

Materials with a strain-hardening exponent equal to 0.08 are also shown in Figure 2, from which it can be seen that there is reasonable agreement between the experimental results and the results obtained using the theoretical model. Again, agreement with the results of the numerical simulation 13 can be checked in Figure 4.

When the $Y / E$ value for 1020 steel is used in the numerical simulation developed by Cheng and Cheng ${ }^{13}$, an imi value of approximately 1.12 is obtained, while for AA1350-H18 alloy the simulation gives an imi of 1.15. As the experimental strain-hardening exponent for these materials is different from the value used in the numerical simulation, these results can be considered satisfactory. In fact, they were corroborated by the experimental finding of an imi of 1.11 for 1020 steel tested with a $5 \mathrm{~mm}$ diameter ball.

The poorest prediction of experimental values for the materials in Figure 2 was observed for AA1350-H24 alloy. Two experimental variations observed for this alloy merit further attention: the deviation in yield strength and the deviation in indentation depth profiles.

Changes in yield strength resulted in only small changes in imi: for each $0.02 \mathrm{GPa}$ change in yield strength a 0.01 variation in imi was observed, which is insufficient to affect

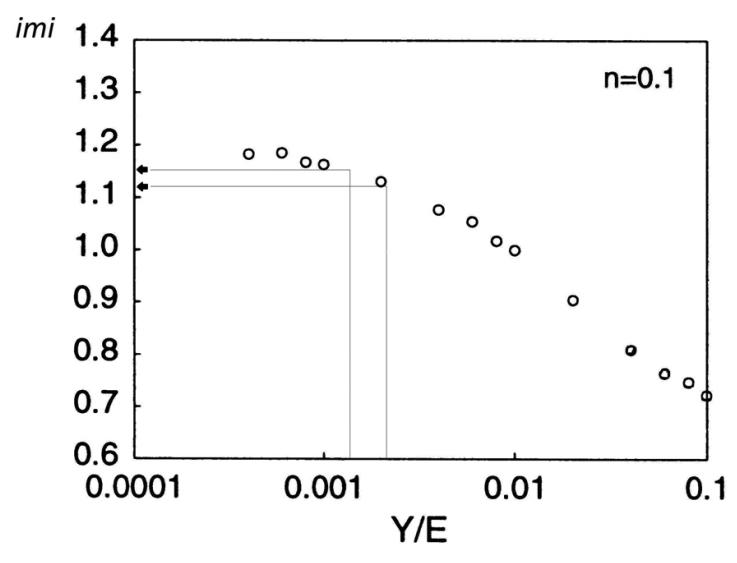

Figure 4. Numerical simulation described by Cheng and Cheng ${ }^{13}$ showing the variation in $i m i$ with $Y / E$ for a material with $n=0.1$. Two experimental values of $Y / E$ and the corresponding values of imi are marked.

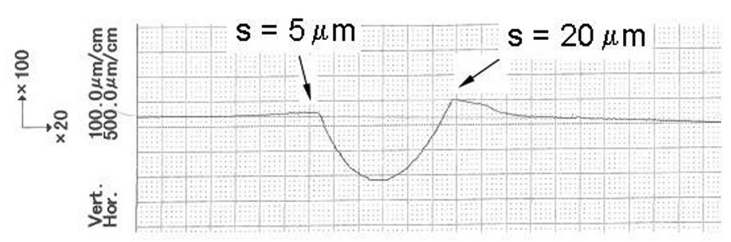

Figure 5. Example of the largest variation in pile-up depth, $s$, for AA1350-H24 alloy tested with a $3.175 \mathrm{~mm}$ diameter ball.

the relationship shown in Figure 2. A possible explanation for the results observed for this alloy may therefore lie in the change in indentation profile.

It can be seen from Figure 5 that the profile after indentation with a $3.175 \mathrm{~mm}$ diameter ball was not uniform and that there were different pile-up depths on either side of the indentation.

Using the average value of $h$ for AA1350-H24 tested with a $3.175 \mathrm{~mm}$ diameter ball $(0.128 \mathrm{~mm})$ and the pile-up depths in Figure 5 to recalculate the imi, the lower pile-up depth gives a value of 1.04 and the higher pile-up depth a value of 1.16 . The former is very close to the value predicted by the model described by Hernot et al. ${ }^{1}$ for this condition (1.05), and the latter to the average experimental values shown in Figure 2 (1.2). Thus, it can be concluded that the greatest pile-up depth observed experimentally resulted in 


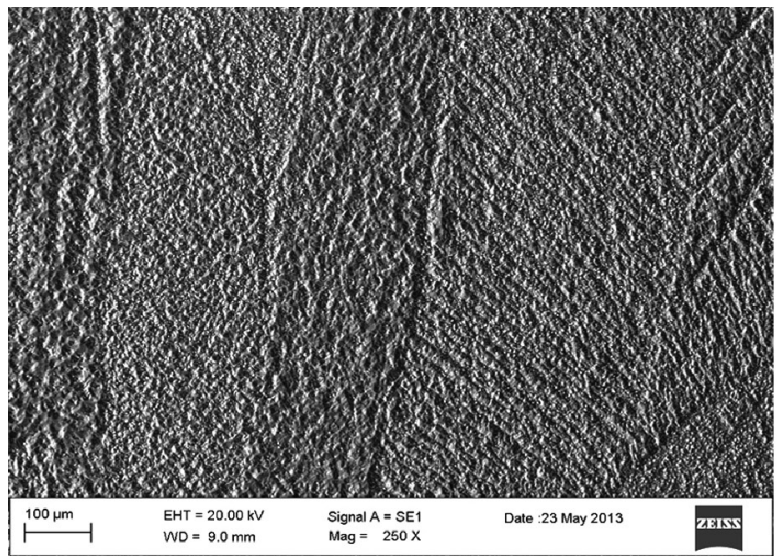

(a)

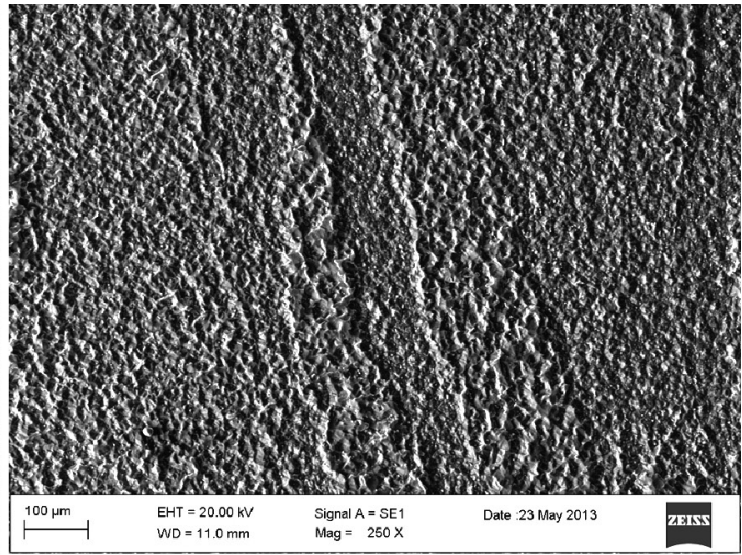

(b)

Figure 6. Microstructure detail of (a) H18 and (b) H24 conditions of AA1350 aluminum alloy, revealed in scanning electron microscope.

an average $i m i$ value quite different from those calculated using the model.

Pintaude et al. ${ }^{4}$ demonstrated a similar effect for wiredrawn 52100 steel, i.e., that pile-up depth was different on each side of the indentation profile after Vickers indentation testing. In addition, Bartier et al. ${ }^{17}$ pointed out that $i m i$ is very sensitive to microstructural inhomogeneities, such as precipitates and different grain sizes. The question of microstructural inhomogeneities is relevant in the case of AA1350 alloy. For example, Mishin et al. ${ }^{18}$ found that for cold-rolled AA1050 alloy (0.24 wt. \% Fe - 0.15 wt. \% Si) in the recrystallized state, grain size was related to grain orientation: grains with the same orientation as the rolling texture had a smaller mean size than those with other orientations, resulting in an irregular distribution. Figure 6 presents images of AA1350 alloy in $\mathrm{H} 18$ and $\mathrm{H} 24$ conditions, revealed in scanning electron microscope. The dimension of images corresponds to a typical diameter $(\sim 1 \mathrm{~mm})$ found after indentation with $3.175 \mathrm{~mm}$ ball.

As the differences between the microstructures revealed in Figure 6 are not clear enough to separate a worthy effect of irregular grain distributions, a final hypothesis to explain the results observed for AA1350-H24 alloy can have been caused by the unevenness in plane of the specimen surface, although all efforts were made to avoid this effect during the specimens' preparation.

As the discrepancies observed with AA1350-H24 alloy are satisfactorily accounted for by the above explanations, it

\section{References}

1. Hernot X, Bartier O, Bekouche Y, Mauvoisin G and El Abdi R. Influence of penetration depth and mechanical properties on contact radius determination for spherical indentation. International Journal of Solids and Structures. 2006; 43:4136-4153. http://dx.doi.org/10.1016/j. ijsolstr.2005.06.007

2. Bolshakov A and Pharr GM. Influences of pileup on the measurement of mechanical properties by load and depth sensing indentation techniques. Journal of Materials can be concluded that the model proposed by Hernot et al. ${ }^{1}$ successfully predicted almost all the experimental results reported here and can therefore be considered a reliable tool for describing indentation morphologies.

\section{Conclusions}

The model proposed by Hernot et al. ${ }^{1}$ to predict indentation morphologies was tested for two aluminum alloys and one type of steel with strain-hardening exponents of less than 0.4 . The results can be considered satisfactory even for low $Y / E$ values. Although the residual indentation profiles of only one type of material were not detected by the model, this could be accounted for by the fact that the pileup depths for this material differed significantly from those for the other materials investigated. This exceptional case was discussed in terms of microstructural inhomogeneities in an attempt to explain the discrepancy in pile-up depths. Although the model proposed by Hernot et al. ${ }^{1}$ failed to predict the imi for this material, it can be considered a reliable tool for predicting indentation morphologies using tensile properties.

\section{Acknowledgments}

Financial support for this study was provided by $\mathrm{CNPq}$ under project no. 306727/2011-0. The authors are grateful to Denso do Brasil for providing the equipment used in the study.

Research. 1998; 13:1049-1058. http://dx.doi.org/10.1557/ JMR.1998.0146

3. Franco AR Jr, Pintaude G, Sinatora A, Pinedo CE and Tschiptschin AP. The Use of Vickers Indenter in Depth Sensing Indentation for Measuring Elastic Modulus and Vickers hardness. Materials Research. 2004; 7:483-491. http://dx.doi. org/10.1590/S1516-14392004000300018

4. Pintaude G, Cuppari MGV, Schon CG, Sinatora A and Souza RM. A review on the reverse analysis for the extraction of mechanical properties using instrumented Vickers indentation. 
International Journal of Materials Research. 2005; 96:12521255.

5. Dao M, Chollacoop N, Van Vliet KJ, Venkatesh TA and Suresh S. Computational modeling of the forward and reverse problems in instrumented sharp indentation. Acta Materialia. 2001; 49:3899-3918. http://dx.doi.org/10.1016/ S1359-6454(01)00295-6

6. Santos AF, Wiebeck H, Souza RM and Schon CG. Instrumented indentation testing of an epoxy adhesive used in automobile body assembling. Polymer Testing. 2008; 27:632-637. http:// dx.doi.org/10.1016/j.polymertesting.2008.04.002

7. Pintaude G. Hoechele AR and Cipriano GL. Relation between Strain-Hardening Exponent of Metals and Residual Profiles of Deep Spherical Indentation. Materials Science and Technology. 2012; 28:1051-1054. http://dx.doi.org/10.1179/1 743284711Y.0000000107

8. Norbury A and Samuel T. The recovery and sinking-in or pilingup of material in the Brinell test, and the effects of these factors on the correlation of the Brinell with certain other hardness tests. Journal of Iron Steel Institute. 1928; 117:673-687.

9. Matthews JR. Indentation Hardness and Hot Pressing. Acta Metallurgica et Materialia. 1980; 28:311-318. http://dx.doi. org/10.1016/0001-6160(80)90166-2

10. Hill R, Stôrakers B and Zdunek AB. A theoretical study of the Brinell Hardness test. Proceedings of the Royal Society of London A. 1989; 423:301-330. http://dx.doi.org/10.1098/ rspa.1989.0056

11. Taljat B, Zacharias T and Kosel T. New analytical procedure to determine stress-strain curve from spherical indentation data.
International Journal of Solids and Structures. 1998; 35:44114426. http://dx.doi.org/10.1016/S0020-7683(97)00249-7

12. Alcalá J, Barone AC and Anglada M. The influence of plastic hardening on surface deformation modes around Vickers and spherical indents. Acta Materialia. 2000; 48:3451-3464. http:// dx.doi.org/10.1016/S1359-6454(00)00140-3

13. Cheng Y-T and Cheng C-M. What is indentation hardness?. Surface and Coatings Technology. 2000;133-134:417-424. http://dx.doi.org/10.1016/S0257-8972(00)00896-3

14. American Society for Testing and Materials - ASTM. E1012: Standard Test Methods for Brinell Hardness of Metallic Materials. ASTM; 2012.

15. Birol Y. Recystallization of twin-foil cast Al-Fe-Si foil stock processed without homogeneization. Journal of Alloys and Compounds. 2009; 488:112-116. http://dx.doi.org/10.1016/j. jallcom.2009.08.135

16. American Society for Testing and Materials - ASTM. E646-07: Standard Test Method for Tensile Strain-Hardening Exponents (n-Values) of Metallic Sheet Materials. ASTM; 2007.

17. Bartier O, Hernot $X$ and Mauvoisin G. Theoretical and experimental analysis of contact radius for spherical indentation. Mechanics of Materials. 2010; 42:640-656. http:// dx.doi.org/10.1016/j.mechmat.2010.03.003

18. Mishin OV, Juul Jensen D and Hansen N. Evolution of Microstructure and Texture during Annealing of Aluminum AA1050 Cold Rolled to High and Ultrahigh Strains. Metallurgical and Materials Transactions A. 2010; 41A:29362947. 